Fourth International Conference on Sustainable Construction Materials and Technologies http://www.claisse.info/Proceedings.htm

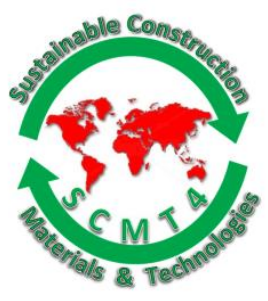

SCMT4

Las Vegas, USA, August 7-11, 2016

\title{
Natural Pozzolan Contained Self-Consolidating Concrete
}

\author{
Nader Ghafoori ${ }^{1 \mathrm{a}}$, MohammadReza Sharbaf ${ }^{1 \mathrm{~b}}$, Meysam Najimi ${ }^{1 \mathrm{c}}$, Iani Batilov ${ }^{1 \mathrm{~d}}$ \\ ${ }^{1}$ Department of Civil and Environmental Engineering and Construction, University of Nevada Las Vegas, \\ 4505 Maryland Parkway, Las Vegas, Nevada, USA, 89154-4015. \\ ${ }^{1 a}$ Email: <nader.ghafoori@unlv.edu>, ${ }^{1 b}$ Email: <sharbaf@unlv.nevada.edu>, \\ ${ }^{I c}$ Email: <najimim@unlv.nevada.edu>, ${ }^{l d}$ Email: 〈batilovi@unlv.nevada.edu>.
}

\begin{abstract}
This paper evaluates the mechanical and transport properties of self-consolidating concrete containing natural pozzolan. To this end, self-consolidating concretes with natural pozzolan replacement ratios of 0 , $15,22.5,30$, and $37.5 \%$ by mass of Portland cement were prepared. Constant water-to-cementitious materials ratio of 0.4 and cementitious materials content of $475 \mathrm{~kg} / \mathrm{m} 3$ were used. The evaluated properties included slump flow, J-ring, $\mathrm{T}_{50}$, compressive strength, modulus of elasticity, water absorption, void content, rapid chloride permeability, rapid chloride migration, and Florida corrosion impressed current test.
\end{abstract}

The results of this investigation showed that fresh and transport properties of SCC mixtures were improved with increases in the replacement level of natural pozzolan. On the other hand, slight reductions were observed in early and mid-aged strength properties of the studied natural pozzolan contained selfconsolidating concretes.

\section{INTRODUCTION}

Based on the U.S. Geological Survey (USGS) conducted on 2015, 4.2 billion tons of cement is produced annually in the world (USGS 2015). In spite of all the energy efficiency efforts in cement industry in the past two decades, about $0.87 \mathrm{~kg}$ of Carbon Dioxide $(\mathrm{CO} 2)$ is generated through production of $1 \mathrm{~kg}$ of clinker. Almost half of these emissions are because of the fuel combustion required to generate heat for the chemical reactions in clinker formation process. The other half are due to limestone calcination as a chemical reaction progress. For calcination of each kilogram of calcium carbonate to produce calcium oxide in the kiln, almost $0.44 \mathrm{~kg}$ of Carbon Dioxide are released. Averagely, $78 \%$ of cement mass is grinded clinker (WBCSD 2009). Therefore, annual CO2 emission due to cement production is 2.8 billion tons worldwide, which is more than $7 \%$ of the global emissions from fossil fuel combustion (P.K. Mehta 2014).

As the environmental aspects of concrete industry are quite considerable, a great deal of research has been devoted to reduction of Portland cement consumption. Use of supplementary cementitious materials, such as fly ash (Mehta, High-performance, high-volume fly ash concrete for sustainable development 2004), 
slag (Mehta, Reducing the environmental impact of concrete 2001), and natural pozzolan (Meyer 2009), has been found effective for production of more environmental friendly concretes. A study conducted by Tomkins (Augustine, et al. 2009) reported that "the biggest single opportunity for $\mathrm{CO}_{2}$ reduction is a lowcarbon cement." It also revealed that by replacing 50\% of Portland cement mass with low-carbon alternatives, the $\mathrm{CO}_{2}$ emission would decrease by 1 billion ton annually. Moreover, use of supplementary cementitious materials, yield mixtures with better durability, mechanical properties, and workability (P.K. Mehta 2014).

Natural Pozzolan (NP) is one of the supplementary cementitious materials which has been utilized successfully in many vibratory-placed concrete projects as a low-cost alternative to Ordinary Portland Cement (OPC) (Shannag 2000, Najimi, et al. 2012, Pekmezci and Akyüz 2004). However, there are a few studies reported on the use of NP in Self Consolidating Concrete (SCC). Celik et al. (Celik, et al. 2014) incorporated Saudi Arabian alumina-silica rich basaltic glass as a natural pozzolan in SCC. An increase in the amount of NP, as a partial replacement of OPC, resulted in a decrease in the required superplasticizer content or $\mathrm{T}_{50}$ which implied an increase in the flowability of the studied concretes. While in 30\% replacement, the NP contained SCCs had the same compressive strength as the reference concrete, it had a lower compressive strength at the ages 7,28, 91 and 365 days when $50 \%$ by mass of OPC was replaced by NP. The results of this study also revealed that incorporation of natural pozzolan in SCCs reduced gas permeability and chloride penetration migration coefficient of concrete.

Belaidi et al. (Belaidi, et al. 2012) examined the effects of substitution of cement with natural pozzolan on the rheological and mechanical properties of SCC. They observed an improvement of workability in the SCCs containing up to $15 \%$ of NP to replace a portion of cement mass. However, the workability of 20 and 25\% NP-contained concretes decreased significantly as compared to that of the reference mix. A reduction of compressive strength was observed with inclusion of NP as compared to reference concrete. The results indicated that NP increases strength at late age curing (90 days and beyond).

Said et al. (Siad 2010) compared the hydrochloric and sulfuric acid behaviours of SCCs containing Algerian natural pozzolan with SCC containing limestone powder. They found that, the NP-contained SCCs were stronger than the limestone powder-contained SCCs.

In an attempt to have a full spectrum of properties examined, the study presented herein reports on fresh, mechanical, and transport properties of natural pozzolan-contained self-consolidating concrete. Moreover, the findings are compared to the properties of the companion reference concrete.

\section{MATERIALS AND MIXTURE PROPORTIONS}

The materials used in this study included Type V Portland cement and natural pozzolan as the binders, fine and coarse aggregates, high range water-reducing admixture, and distilled water. The chemical compositions of Portland cement and natural pozzolan are presented in Table 1. A comparison between physico-chemical properties of the natural pozzolan and the requirements of ASTM C618 (ASTM C61815 2015) is shown in Table 2. As can be seen, the used natural pozzolan contained $78.4 \%$ of pozzolanic oxides (silica, alumina, and iron oxides). The calcium oxide content was low (3.2\%), indicating that the used natural pozzolan was not cementitious on its own. The 7- and 28-day strength of mortars having $20 \%$ natural pozzolan were 85 and $92 \%$ of those of the prepared standard reference mortar, respectively. These strength results are well above the minimum requirement of $75 \%$ specified in ASTM C672 (ASTM C672 / C672M-12 2012). The fine $(0-4.75 \mathrm{~mm})$ and coarse $(4.75-12.5 \mathrm{~mm})$ aggregates passing the gradation size requirements of ASTM C33 (ASTM C33 / C33M-16 2016) were used in this study. Their physical properties are reported in Table 3. A Polycarboxylate-based High Range Water-Reducing 
Admixture (HRWRA), complying with the requirements of ASTM C 494 (ASTM C494 / C494M-15a 2015) Type F, was also utilized.

Table 4 summarizes the mixture proportions and constituents of the studied SCCs. In addition to the reference concrete (without natural pozzolan (NP0)); four natural pozzolan-contained SCCs were batched by replacing $15,22.5,30$, and $37.5 \%$ of Portland cement mass with natural pozzolan (NP15, NP22.5, NP30, and NP37.5, respectively). In an attempt to achieve a uniform target flowability (spread flow of $673 \pm 25 \mathrm{~mm}(26.5 \pm 1 \mathrm{in})$, and visual stability index of zero), different amounts of superplasticizer were used, as shown in Table 4.

Table 1. Chemical composition of utilized cement and natural pozzolan

\begin{tabular}{|c|c|c|}
\hline Compound/property & Type V Portland cement & Natural pozzolan \\
\hline Calcium oxide $(\mathrm{CaO})$ & 61.32 & 3.2 \\
\hline Silicon Dioxide $\left(\mathrm{SiO}_{2}\right)$ & 21.68 & 68.8 \\
\hline Aluminum Oxide $\left(\mathrm{Al}_{2} \mathrm{O}_{3}\right)$ & 4.85 & 8.5 \\
\hline Iron oxide $\left(\mathrm{Fe}_{2} \mathrm{O}_{3}\right)$ & 4.40 & 1.1 \\
\hline Magnesium oxide $(\mathrm{MgO})$ & 2.60 & --- \\
\hline Sodium oxide $\left(\mathrm{Na}_{2} \mathrm{O}\right)$ & 0.25 & 2.6 \\
\hline Potassium oxide $\left(\mathrm{K}_{2} \mathrm{O}\right)$ & 0.71 & 3.9 \\
\hline Sulfur trioxide $\left(\mathrm{SO}_{3}\right)$ & 1.90 & 0.1 \\
\hline
\end{tabular}

Table 2. Chemical and physical properties of natural pozzolan according to ASTM C618 (ASTM C618-15 2015)

\begin{tabular}{|c|c|c|}
\hline Chemical requirements & $\begin{array}{c}\text { Class N, ASTM } \\
\text { C618 }\end{array}$ & $\begin{array}{c}\text { Natural pozzolan } \\
\text { results }\end{array}$ \\
\hline $\mathrm{SiO}_{2}+\mathrm{Al}_{2} \mathrm{O}_{3}+\mathrm{Fe}_{2} \mathrm{O}_{3}(\%)$ & Min, 70.0 & 78.4 \\
\hline Sulfur trioxide $\left(\mathrm{SO}_{3}\right)(\%)$ & Max, 4.0 & 0.1 \\
\hline Moisture content (\%) & Max, 3.0 & 0.7 \\
\hline Loss on ignition (\%) & Max, 10.0 & 3.4 \\
\hline Physical requirements & & 2.29 \\
\hline Density & --- & 6088 \\
\hline Blaine & --- & 9.4 \\
\hline Amount retained when wet-sieved on $45 \mu \mathrm{m}(325$ mesh) & Max, 34 & 85 \\
\hline sieve (\%) & Min, 75 & 92 \\
\hline Strength activity index, at 7 days, percent of control* & Min, 75 & 98 \\
\hline Water requirement, percent of control & Max, 115 & 0.00 \\
\hline Autoclave expansion or contraction $(\%)$ & Max, 0.8 & \\
\hline
\end{tabular}

*Note that, the activity index of natural pozzolan is determined based on ASTM C311 (ASTM C311 / C311M-13 2013) by replacing $20 \%$ of cement with natural pozzolan. 
Table 3. Aggregate properties

\begin{tabular}{|c|c|c|c|}
\hline Aggregate type & $\begin{array}{c}\text { Specific gravity (Oven- } \\
\text { Dry) }\end{array}$ & $\begin{array}{c}\text { Specific Gravity (Saturated- } \\
\text { Surface Dry) }\end{array}$ & $\begin{array}{c}\text { Water absorption } \\
(\%)\end{array}$ \\
\hline Fine $(0-4.75 \mathrm{~mm})$ & 2.755 & 2.777 & 0.81 \\
\hline $\begin{array}{c}\text { Coarse }(4.75- \\
12.5 \mathrm{~mm})\end{array}$ & 2.747 & 2.768 & 0.79 \\
\hline
\end{tabular}

Table 4. Mixture proportions

\begin{tabular}{|c|c|c|c|c|c|c|c|c|c|}
\hline Mix ID & $\begin{array}{c}\text { NP } \\
\text { Dosage } \\
(\% \text { by } \\
\text { mass of } \\
\text { binder })\end{array}$ & $\begin{array}{c}\text { Water } \\
\text { to } \\
\text { binder } \\
\text { ratio }\end{array}$ & $\begin{array}{c}\text { Cement } \\
\left(\mathrm{kg} / \mathrm{m}^{3}\right)\end{array}$ & $\begin{array}{c}\text { Natural } \\
\text { pozzolan } \\
\left(\mathrm{kg} / \mathrm{m}^{3}\right)\end{array}$ & $\begin{array}{c}\text { Water } \\
\left(\mathrm{kg} / \mathrm{m}^{3}\right)\end{array}$ & $\begin{array}{c}\text { Fine } \\
\text { Agg. } \\
\left(\mathrm{kg} / \mathrm{m}^{3}\right)\end{array}$ & $\begin{array}{c}\text { Coarse } \\
\text { Agg. } \\
(4.75-9 \\
\mathrm{mm}) \\
\left(\mathrm{kg} / \mathrm{m}^{3}\right)\end{array}$ & $\begin{array}{c}\text { Coarse } \\
\text { Agg. }(9- \\
12.5 \\
\mathrm{~mm}) \\
\left(\mathrm{kg} / \mathrm{m}^{3}\right)\end{array}$ & $\begin{array}{c}\text { Admixture } \\
\left(\mathrm{kg} / \mathrm{m}^{3}\right)\end{array}$ \\
\hline NP0 & 0 & 0.40 & 475 & 0.00 & 190 & 1004.7 & 416.9 & 341.1 & 2.593 \\
\hline NP15 & 15 & 0.40 & 403.75 & 71.25 & 190 & 992.7 & 411.9 & 337 & 2.490 \\
\hline NP22.5 & 22.5 & 0.40 & 368.1 & 106.9 & 190 & 986.7 & 409.4 & 335 & 2.278 \\
\hline NP30 & 30 & 0.40 & 332.5 & 142.5 & 190 & 980.7 & 406.9 & 332.9 & 2.126 \\
\hline NP37.5 & 37.5 & 0.40 & 296.9 & 178.1 & 190 & 974.7 & 404.4 & 330.9 & 2.035 \\
\hline
\end{tabular}

$*$ Total binder content $=475 \mathrm{~kg} / \mathrm{m}^{3}$

\section{MIXING AND TESTING METHODS}

A counter-current horizontal pan mixer with $0.0283 \mathrm{~m} 3(1 \mathrm{ft} 3)$ capacity was used to batch the studied concrete. For the mixing sequence, first the coarse aggregate and $1 / 3$ of the mixing water was added. Following the first 2 minutes of mixing, the fine aggregate and $1 / 3$ of the water was incorporated and mixed for another 2 minutes. Afterward, the cement, natural pozzolan and remaining water was added. After mixing for 2 minutes, the HRWRA was slowly introduced and allowed to mix for an additional 2 minutes. At this point, fresh concrete was allowed to rest for 2 minutes before remixing resumed for one minute. The elapsed time of the total mixing sequence was 11 minutes or 7 minutes once cement became in contact with water. Immediately after mixing, freshly-mixed concretes were poured in molds without any external vibration. After casting, specimens were kept covered in the laboratory for 24 hours (room temperature of $23 \pm 1{ }^{\circ} \mathrm{C}$ ) before being demolded and placed in a moisture room to cure for different ages prior to testing.

The slump flow and dynamic stability expressed in Visual Stability Index (VSI) for the studied SCCs were measured based on ASTM C1611 (ASTM C1611 / C1611M-14 2014) standard. The $\mathrm{T}_{50}$ test was evaluated based on ASTM C1611. The J-ring test ASTM C1621 (ASTM C1621 / C1621M-14 2014) was used to determine the passing ability of self-consolidating concretes.

Cylindrical specimens having dimensions of $76 \times 152 \mathrm{~mm}(3 \times 6$ in) were used to conduct compression tests in accordance with ASTM C39 (ASTM C39 / C39M-16 2016) and C469 (ASTM C469 / C469M-14 2014) to obtain compressive strength and modulus of elasticity, respectively. ASTM C642 (ASTM C64213 2013) was used to measure water absorption and void content of the studied SCC at the ages of 28 and 
90 days. Rapid chloride permeability test (ASTM C1202-12 2012) and rapid migration test (NT Build 492 (Built n.d.) or AASHTO TP 64-03 (AASHTO 2003)) were also carried at the ages of 28 and 90 days. Impressed Current test was conducted conforming to Florida Method of Test designation FM 5-522 (Brown and Kessler 1978) to evaluate the corrosion resistance of SCC specimens. Cylindrical shaped specimens in size of $102 \times 146 \mathrm{~mm}(4 \times 5.75 \mathrm{in})$ were cast with a No. 4 rebar partially embedded. After 28 days of curing, the samples were placed in a tank with $5 \% \mathrm{NaCl}$ solution. The level of solution was kept $75 \mathrm{~mm}(3 \mathrm{inch})$ above the bottom of the specimens for an additional 28 days. Afterward, the exposed rebar was connected to the positive output terminal of a half-wave rectifier. The negative terminal of the power supply was connected to a piece of rebar in the tank. The DC power supply was adjusted to 6-volts and the current to each specimen was measured on a daily basis. The measurements were made until the current increased significantly and the specimen failed. Time to failure (days) is reported as the test results.

For all the mentioned tests, at each age three samples were tested and their average value was reported as the value of the related mixture design.

\section{RESULTS AND DISCUSSION}

\section{Fresh Properties}

The measured slump flow, VSI, $\mathrm{T}_{50}$, and J-ring for each studied mixtures is shown in Table 5. The measurements reported are the average of three tests.

Table 5. Fresh Properties

\begin{tabular}{|c|c|c|c|c|c|}
\hline Mix ID & $\begin{array}{c}\text { Slump Flow } \\
(\mathrm{mm})\end{array}$ & VSI & $\begin{array}{c}\text { HRWRA Dosage }(\% \text { by mass of } \\
\text { binder })\end{array}$ & J-ring $(\mathrm{mm})\left(\mathrm{h}_{2}-\mathrm{h}_{1}\right)$ & $\mathrm{T}_{50}($ Seconds $)$ \\
\hline NP0 & 673 & 0 & 0.546 & 25.4 & 2.61 \\
\hline NP15 & 673 & 0 & 0.524 & 12.7 & 2.34 \\
\hline NP22.5 & 673 & 0 & 0.479 & 6.35 & 2.01 \\
\hline NP30 & 673 & 0 & 0.448 & 12.7 & 2.03 \\
\hline NP37.5 & 673 & 0 & 0.428 & 31.75 & 1.92 \\
\hline
\end{tabular}

As can be seen in Table 5, all SCCs met the target slump flow of $673 \pm 25 \mathrm{~mm}$ ( $26.5 \pm 1 \mathrm{in})$. Moreover, VSI of 0 was recorded for all studied SCCs, indicating an excellent display of dynamic stability, and resistance to bleeding and segregation.

The HRWRA dosage for the studied SCCs decreased with an increase in the amount of NP. The admixture dosage decreased $4,14,22$, and $27 \%$ for the SCCs containing $15,22.5,30$, and $37 \%$ natural pozzolan, respectively, when compared with reference SCC. This is attributed to the $98 \%$ required water for the utilized natural pozzolan as shown in Table 2, which necessitated lesser amount of water to meet the target flowability. 
The J-ring test results, reported as the difference in diameter of slump flow test conducted with and without the J-ring, showed improvements in passing ability of the studied SCCs through partial replacement of cement with natural pozzolan, except for the mixture NP37.5 having $37.5 \%$ natural pozzolan. The mixture NP22.5 containing $22.5 \%$ natural pozzolan showed the best passing ability with 19 $\mathrm{mm}$ lesser J-ring as compared to that of the reference concrete.

The $\mathrm{T}_{50}$ flow times, which indicates the rate of flowability or viscosity (by inference) of mixtures, improved with inclusion of natural pozzolan. $\mathrm{T}_{50}$ of the SCCs containing $15,22.5,30$, and $37.5 \%$ natural pozzolan was $10,23,23$, and $26 \%$ lower than that of reference mixture, respectively.

Improvement in flowability and passing ability of NP-contained SCCs can be due to the reduction in the amount of HRWRA than that reported for the reference SCC. The reduction in HRWRA demand resulted in the NP-contained SCCs to have better viscosity (rate of flow) and improved passing ability (Caldrone, Gruber and Burg 1994).

\section{Mechanical Properties}

Figure 1 reports the results of compression test. The results revealed that the compressive strength decreased with increases in NP content at all ages except for 140 days. The gap in compressive strength between natural pozzolan-contained SCCs and the reference SCC widened with an increase in NP content and narrowed with increases in curing age. The 7-, 28-, and 90-day compressive strength of the NP15 marginally decreased by $7,0.1$ and $0.4 \%$, respectively, as compared to that of the reference concrete. These decreases are minimal and remain within typical concrete variations. Once the natural pozzolan replaced $22.5 \%$ by mass of Portland cement, the compressive strength of NP22.5 experienced a larger drop in compressive strength throughout the first 90 days of curing. The compressive strength of the NP22.5 SCCs decreased by nearly 21,10 , and $4 \%$ at the age of 7,28 , and 90 day of curing, respectively, when compared to that of the reference concrete. By replacing 30\% of Portland cement by NP, the compressive strength of SCC samples was 24, 11, and 9\% lower than those of reference SCC at the same curing age, respectively. With increased natural pozzolan content to $37.5 \%$, the compressive strength decreased by approximately 32,19 , and $15 \%$ at the curing age of 7,28 , and 90 days, respectively, when compared to those the reference mixture. When curing age was extended to 140 days, the compressive strength of NP15, NP22.5, and NP30 SCCs surpassed that of the reference SCC by 3, 10, and 6\%, respectively. The 140-day compressive strength of NP37.5 SCC was only $2 \%$ lower than that of NP0. These findings are similar to those reported by Belaidi et al. (Belaidi, et al. 2012).

Modulus of Elasticity (MOE) of the studied SCCs are shown in Figure 2. As can be seen, elastic modulus of the studied SCC mixtures decreased with increases in the amount of natural pozzolan. 28-day MOE for NP15, NP22.5, NP30, and NP37.5 decreased by roughly 3, 7, 8, and $16 \%$, respectively, as compared to that reported for the reference SCC. When natural pozzolan replaced 15, 22.5, 30, and $37.5 \%$ by mass of Portland cement, the 90-day MOE of the studied SCCs averagely decreased $4 \%$ when compared to that obtained for the reference concrete.

The observed decrease in the strength of SCCs due to the inclusion of NP can be explained by the fact that the large amount of pozzolan content (more than 15\%) in concrete leads to the surplus of small-sized particles, resulting in a slow separation of grain particles to cause reduction in packing density and strength of cementitious materials paste (BACHE 1987, Sobolev and Soboleva 1996). It's also related to late reactivity of natural pozzolan as compared to Portland cement. The increase in the strength of the studied NP contained SCCs with curing age is due to the continued pozzolanic reactivity of the cement and Natural Pozzolan, filling the gap between reference and natural pozzolan contained SCCs (Villain, Barogel-Bouny and Kounkou 1999). 

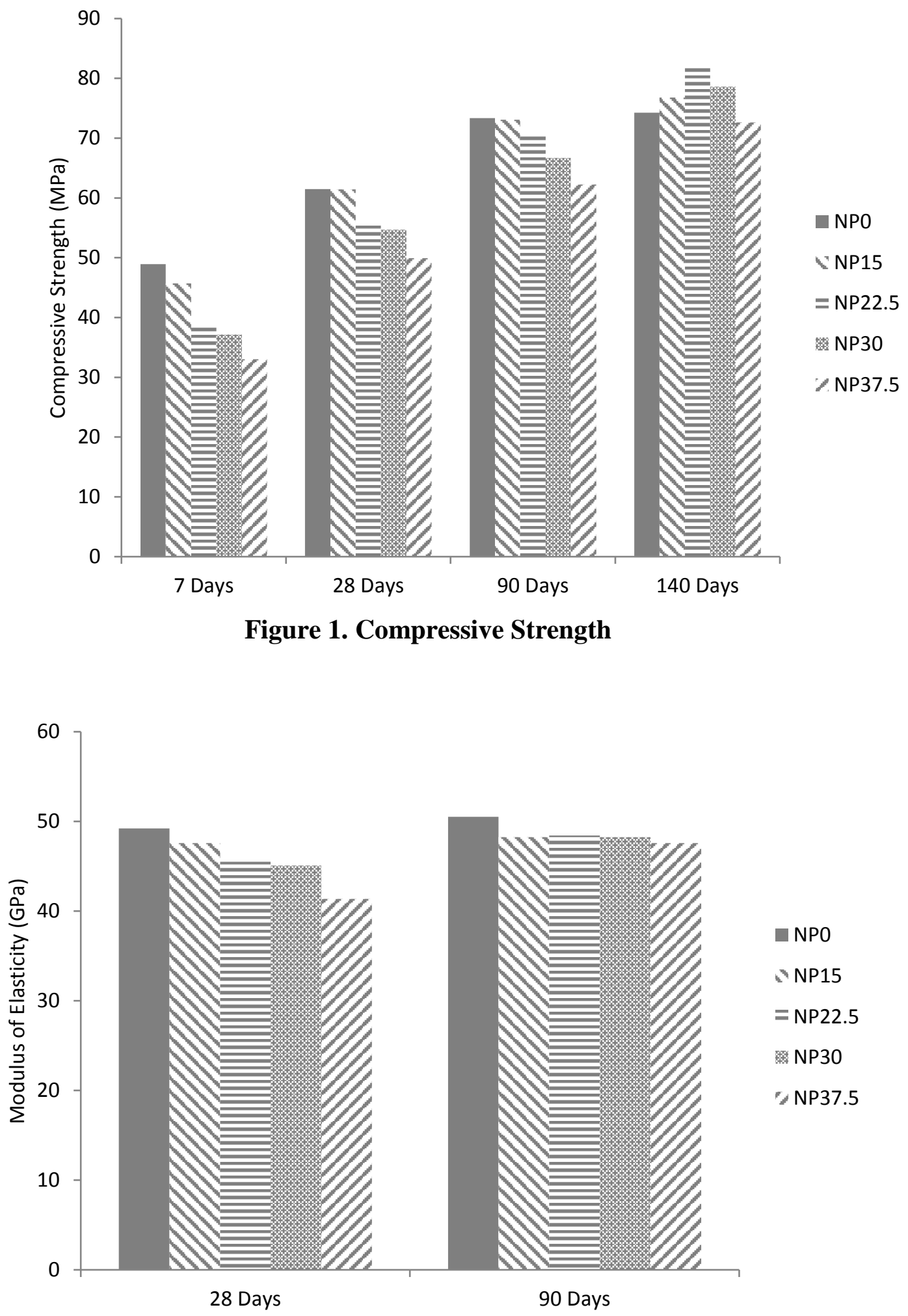

Figure 2. Modulus of Elasticity 


\section{Transport Properties}

Table 6 documents the water absorption and void content of the studied SCC mixtures at the ages of 28 and 90 days. It can be seen that inclusion of natural pozzolan led to improvements in water absorption and void content of SCC mixtures. The 28-day water absorption improved by 16, 20, 21, and 15\% when NP replaced 15, 22.5, 30, and $37.5 \%$ by mass of Portland cement, respectively. For similar replacement levels, the improvements in the 28-day void content were $17,22,23$, and $18 \%$, respectively.

At the age of 90 days, the water absorption of NP15, NP22.5, NP30, and NP37.5 SCCs were 21, 24, 27, and $30 \%$ lower than that of reference concrete, respectively. For the same mixtures, there were 21, 25, 28, and $31 \%$ reductions in the void content, respectively.

Table 6. Water absorption and void content

\begin{tabular}{|c|c|c|c|c|}
\hline \multirow{2}{*}{ Mix ID } & \multicolumn{2}{|c|}{ 28 days } & \multicolumn{2}{c|}{ 90days } \\
\cline { 2 - 5 } & Water absorption (\%) & Void Content (\%) & Water absorption (\%) & Void Content (\%) \\
\hline NP0 & 3.27 & 7.85 & 3.34 & 7.98 \\
\hline NP15 & 2.76 & 6.51 & 2.64 & 6.31 \\
\hline NP22.5 & 2.61 & 6.11 & 2.54 & 6 \\
\hline NP30 & 2.60 & 6.05 & 2.44 & 5.78 \\
\hline NP37.5 & 2.79 & 6.47 & 2.34 & 5.48 \\
\hline
\end{tabular}

The results of Rapid Chloride Permeability Test (RCPT) and Rapid Migration Test (RMT) at the ages of 28 and 90 days are shown in Figure 3. The test results showed improvements in chloride penetration by inclusion of natural pozzolan. The 28-day RCPT decreased by nearly 3, 13, 35, and 39\%, when NP replaced 15, 22.5, 30, and $37.5 \%$ by mass of Portland cement, respectively. For similar replacement levels, the 90-day RCPT improved by approximately 53,67, 76, and 79\%, respectively. For the rapid migration test, an improvement of averagely $6 \%$ was observed at 28 days of curing for all the studied NP contained SCC mixtures as compared to the reference concrete. The 90-day RMT improved by nearly 44, 54,55 , and $66 \%$ when natural pozzolan replaced $15,22.5,30$, and $37.5 \%$ by mass of Portland cement, respectively.

The improvement in the transport properties of NP-contained SCCs could be due to the filler effects of Natural Pozzolan, improving transition zone and providing a denser microstructure (Carette and Malhotra 1992, Yogendran, et al. 1987, ACI 232 1998).

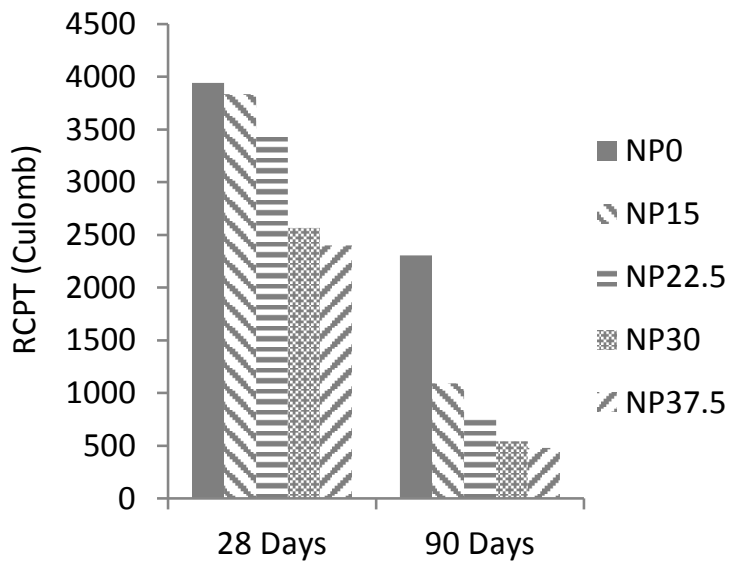

Figure 3-a. RCPT

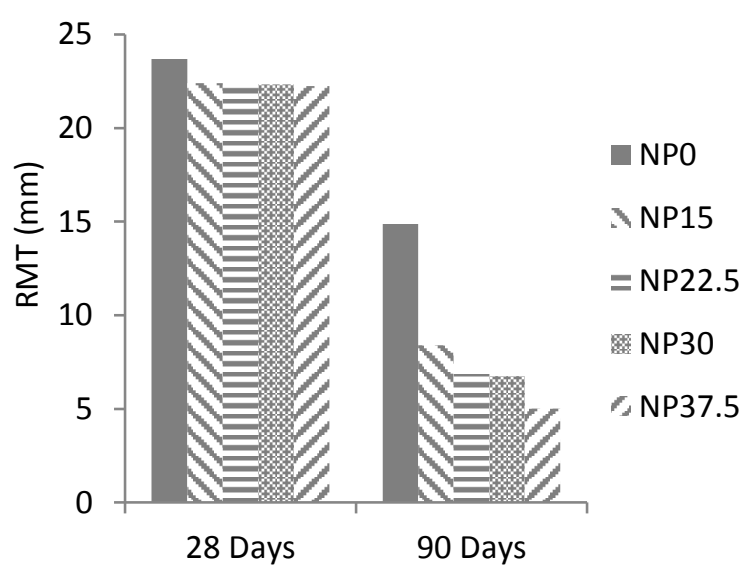

Figure 3-b. RMT 


\section{Corrosion}

The results of corrosion test are shown in Table 7. As can be seen, time to failure of the studied SCC mixtures improved when NP replaced by Portland cement at 90 days of curing.

28-day Florida corrosion time to failure decreased by nearly 22 and 19\% when NP replaced 15 and $22.5 \%$ by mass of Portland cement, respectively, as compared to the reference concrete. While NP30 mixture showed the same time of failure as compared to the reference concrete, NP37.5 mixture showed 56\% improvement at 28 days of curing. At the age of 90 days, while the failure time of NP0, NP15 and NP22.5 were almost the same, use of higher dosage of natural pozzolan led to significant improvement in failure time. The failure time increased by 29 , and $158 \%$ when 30 and $37.5 \%$ of cement was replaced by natural pozzolan, respectively. These results are similar to the findings reported by Fajardo et al. (Fajardo, Valdez and Pacheco 2009) as natural pozzolan contained mixtures would decrease the corrosion rate in longer time of curing ( 90 days and beyond).

Table 7. Florida corrosion impressed current

\begin{tabular}{|c|c|c|}
\hline \multirow{2}{*}{ Mix ID } & \multicolumn{2}{|c|}{ Time to failure (days) } \\
\cline { 2 - 3 } & 28 days & 90 days \\
\hline NP0 & 9 & 19 \\
\hline NP15 & 7 & 18.3 \\
\hline NP22.5 & 7.3 & 19.7 \\
\hline NP30 & 9 & 24.5 \\
\hline NP37.5 & 14 & 49 \\
\hline
\end{tabular}

\section{CONCLUSION}

This study evaluated fresh, mechanical, and transport properties of natural pozzolan contained selfconsolidating concrete. Based on the results of the study, the following conclusions can be drawn:

1. Flow properties of the studied SCCs improved with increases in the amount of Natural Pozzolan.

2. Compressive strength and modulus of elasticity slightly decreased with increases in NP dosage at the curing ages of 7,28 and 90 days. The reductions were narrowed by extending the curing age. At 140-day curing, natural Pozzolan contained SCCs developed similar or superior strength to that of reference SCC.

3. An increase in the amount of NP, as a partial replacement of OPC, resulted in improvement of water absorption, void content, RCPT, RMT, and corrosion rate of the studied SCCs. The improvements were even more significant when longer curing age was used. 


\section{REFERENCES}

AASHTO, TP. "64-03. Standard method of test for prediction of chloride penetration in hydraulic cement concrete by the rapid migration procedure." Washington: American Association of State Highway and Transportation Officials, 2003.

ACI 232, Use of Natural Pozzolans in Concrete. Farmington Hills, MI: ACI Document 232.1R, 1998.

ASTM C1202-12, Standard Test Method for Electrical Indication of Concrete's Ability to Resist Chloride Ion Penetration. West Conshohocken, PA: ASTM International, 2012.

ASTM C1611 / C1611M-14, Standard Test Method for Slump Flow of Self-Consolidating Concrete. West Conshohocken, PA: ASTM International, 2014.

ASTM C1621 / C1621M-14, Standard Test Method for Passing Ability of Self-Consolidating Concrete by J-Ring. West Conshohocken, PA: ASTM International, 2014.

ASTM C311 / C311M-13, Standard Test Methods for Sampling and Testing Fly Ash or Natural Pozzolans for Use in Portland-Cement Concrete. West Conshohocken, PA: ASTM International, 2013.

ASTM C33 / C33M-16, Standard Specification for Concrete Aggregates. West Conshohocken, PA: ASTM International, 2016.

ASTM C39 / C39M-16, Standard Test Method for Compressive Strength of Cylindrical Concrete Specimens. West Conshohocken, PA: ASTM International, 2016.

ASTM C469 / C469M-14, Standard Test Method for Static Modulus of Elasticity and Poisson's Ratio of Concrete in Compression. West Conshohocken, PA: ASTM International, 2014.

ASTM C494 / C494M-15a, Standard Specification for Chemical Admixtures for Concrete. West Conshohocken, PA: ASTM International, 2015.

ASTM C618-15, Standard Specification for Coal Fly Ash and Raw or Calcined Natural Pozzolan for Use in Concrete. West Conshohocken, PA: ASTM International, 2015.

ASTM C618-15, Standard Specification for Coal Fly Ash and Raw or Calcined Natural Pozzolan for Use in Concrete. West Conshohocken, PA: ASTM International, 2015.

ASTM C642-13, Standard Test Method for Density, Absorption, and Voids in Hardened Concrete. West Conshohocken, PA: ASTM International, 2013.

ASTM C672 / C672M-12, Standard Test Method for Scaling Resistance of Concrete Surfaces Exposed to Deicing Chemicals. West Conshohocken, PA: ASTM International, 2012.

Augustine, C, A Byrne, I Hoffman, E Gimon, T Goerner, and D Kammen. "Redefining What's Possible for Clean Energy by 2020." Gigaton Throwdown: Jun, 2009.

BACHE, HANSHENRIK. "High-strength concrete development through 25 years." 1987.

Belaidi, ASE, L Azzouz, E Kadri, and S Kenai. "Effect of natural pozzolana and marble powder on the properties of self-compacting concrete." Construction and Building Materials 31 (2012): 251-257.

Brown, RP, and Richard J Kessler. "An accelerated laboratory method for corrosion testing of reinforced concrete using impressed current." 1978.

Built, NT. "492 (1999) Chloride migration coefficient from non-steady-state migration experiments." Nordic council minister, n.d. 
Caldrone, MA, KA Gruber, and RG Burg. "High reactivity MEtakaolin: a new generation mineral admixture for high performance concrete." Concrete International 16 (1994): 11.

Carette, GG, and VM Malhotra. "Longterm Strength Development of Silica Fume Concrete." Special Publication 132 (1992): 1017- 1044.

Celik, Kemal, Cagla Meral, Mauricio Mancio, P Kumar Mehta, and Paulo JM Monteiro. "A comparative study of self-consolidating concretes incorporating high-volume natural pozzolan or high-volume fly ash." Construction and Building Materials 67 (2014): 14-19.

Fajardo, G, P Valdez, and J Pacheco. "Corrosion of steel rebar embedded in natural pozzolan based mortars exposed to chlorides." Construction and Building Materials 23, no. 2 (2009): 768-774.

Felekoğlu, Burak, and Hasan Sarıkahya. "Effect of chemical structure of polycarboxylate-based superplasticizers on workability retention of self-compacting concrete." Construction and Building Materials 22, no. 9 (2008): 1972-1980.

Mehta, P Kumar. "High-performance, high-volume fly ash concrete for sustainable development." Proceedings of the international workshop on sustainable development and concrete technology. 2004. 3-14.

Mehta, P Kumar. "Reducing the environmental impact of concrete." Concrete International 23, no. 10 (2001): 61-66.

Meyer, Christian. "The greening of the concrete industry." Cement and Concrete Composites 31, no. 8 (2009): 601- 605.

Najimi, Meysam, Jafar Sobhani, Babak Ahmadi, and Mohammad Shekarchi. "An experimental study on durability properties of concrete containing zeolite as a highly reactive natural pozzolan." Construction and Building Materials 35 (2012): 1023-1033.

P.K. Mehta, P.J.M. Monteiro. Concrete: microstructure, properties, and materials. 4th Edition. McGrawHill, 2014.

Pekmezci, BY, and S Akyüz. "Optimum usage of a natural pozzolan for the maximum compressive strength of concrete." Cement and Concrete Research 34, no. 12 (2004): 2175-2179.

Shannag, MJ. "High strength concrete containing natural pozzolan and silica fume." Cement and Concrete Composites 22, no. 6 (2000): 399- 406.

Siad, Hocine. "Influence of natural pozzolan on the behavior of self-compacting concrete under sulphuric and hydrochloric acid attacks, comparative study." 2010.

Sobolev, KG, and SV Soboleva. "High strength concrete mix design and properties optimization, concrete technology in developing countries." Proceedings of the 4th International Conference, Famagusta, TRNC. 1996. 189-202.

USGS. Mineral Commodity Summaries. Cement Statistics and Information, United States Geological Survey, USGS, 2015, 38-39.

Villain, G, V Barogel-Bouny, and C Kounkou. "Comparative study on the induced hydration, drying and deformations of self-compacting and ordinary mortars." Proceedings of the First International RILEM Symposium. 1999. 131-142.

WBCSD, IEA. "Cement Technology Roadmap 2009: Carbon Emissions Reductions up to 2050." World Business Council for Sustainable Development and International Energy Agency.< http://wbcsdcement.org/pdf/technology/WBCSD-IEA_Cement\% 20Roadmap.pdf, 2009. 
Yogendran, Vf, BW Langan, MN Haque, and MA Ward. "Silica fume in high strength concrete." ACI Materials Journal 84, no. 2 (1987): 124-129. 